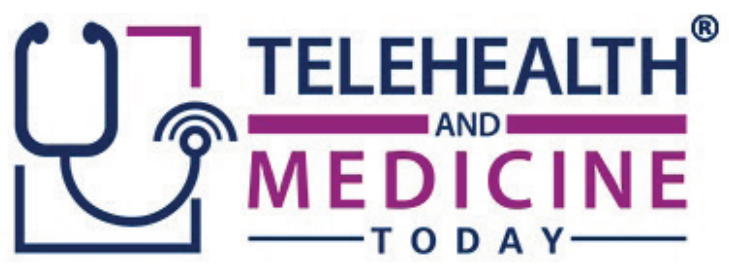

\title{
Telehealth Finance Variables and Successful Business Models
}

\author{
Bryan T. Arkwright ${ }^{1,2,3,4}$, Monica Leslie ${ }^{4}$, Morgan Light ${ }^{1}$
}

Affiliations: 'School of Law, Wake Forest University, Winston-Salem, NC, USA; ${ }^{2}$ Cromford Health, Charlotte, NC, USA; ${ }^{3}$ Partners in Digital Health, New York, NY, USA; ${ }^{4}$ Schumacher Clinical Partners, Lafayette, LA, USA

Corresponding Author: Bryan T. Arkwright, Email: arkwribt@wfu.edu or bryan@cromfordhealth.com

Keywords: Business Model, Governance, Compliance, Data, Data Analytics Digital Health, Finance, Health System, Hospital, Leadership, Regulatory, ROI, Startup, Sustainability, Telehealth, Telemedicine, Value, Vendor, Viability, VOI

Category: Original Market Research, Methodologies

Successful telehealth business models are a topic of regular discussion in the healthcare industry, and the financial details of telehealth programs, initiatives, and companies are central to program viability and sustainability. Claims and total payments toward telehealth services are rapidly increasing each year; therefore, it is becoming imperative that organizations carefully navigate the regulatory, financial, operational, and technical aspects impacting, and many times determining, the financial health of telehealth programs. The objective of this article is to define and articulate the financial variables and business models that are the lifeblood of today's successful telehealth programs, and also to provide insights and information to assist organizations in navigating the nuances of telehealth financial modeling, monitoring, and management.
The financial and business models surrounding telehealth are unique for a number of reasons, mainly because the calculations and architecture of such models often contain many continuous variables, such as people (clinical providers and patients), geography (rural or metropolitan areas), telehealth governance structure, the service provided, the reimbursement or coverage eligibility, the technology used, the quality of care rendered, and the outcome of the care rendered. In addition, a clear need for a departure from traditional ways of projecting return on investment (ROI) becomes apparent with the layering of additional complexities of restrictive payer requirements, various business models, and the transition from volume to value. 
$\mathrm{S}$ uccessful telehealth business models are a topic of regular discussion in the healthcare industry, and the financial details of telehealth programs, initiatives, and companies are at the center of the debate. The aim of this article is to define and articulate the financial variables and business models that are the lifeblood of today's successful telehealth programs.

\section{TELEHEALTH FINANCE VARIABLES}

The financial and business models surrounding telehealth are unique for a number of reasons, mainly because the calculations and architecture of such models often contain many continuous variables. ${ }^{1}$ The continuous variables of telehealth finance and business models include people (clinical providers and patients), geography (rural or metropolitan areas), telehealth governance structure, the service provided, the reimbursement or coverage eligibility, the technology used, the quality of care rendered, and the outcome of the care rendered. These continuous variables can make it challenging to actuate financial sustainability and determine if or when a telehealth program, initiative, or company has a successful business model. "In any case, healthcare managers facing a decision must deal with the phenomenon known as bounded rationality, or the limits imposed on decision making by costs, human abilities and errors, time, technology, and the tractability of data," asserts Yasar Ozcan, vice chair and director, Master of Science in Health Administration of Virginia Commonwealth University. ${ }^{2}$ Telehealth adds another layer of complexity on top of an industry that already has data tractability challenges due to the nature of data being generated and collected at two distinct locations (patient side and clinical provider side). Traditional business models in industries outside of healthcare have more defined, stable, and tractable data inputs and outputs.
In this article, first, the authors strive to list the variables of telehealth finance and describe how they can be organized for a successful telehealth business model. Then they provide a review of prevalent business models used by telehealth programs, initiatives, and companies, examining the return on investment (ROI) and value on investment (VOI) calculations for determining financial sustainability. Finally, the authors conclude with telehealth governance and a discourse of how leadership and management principles apply to telehealth programs, initiatives, and companies.

Table 1 lists and defines telehealth finance variables present in telehealth programs, initiatives, and companies.

Awareness of the breadth of telehealth finance variables is essential for the operations of successful telehealth programs, initiatives, and companies. Furthermore, the laws and regulations of US states, US federal initiatives, and additional countries and states outside the United States create major confusion across stakeholders in the industry. A lack of defined standards and varied definitions of industry terms, business models, and financing mechanisms by the active players contribute to this. Confusion is often a byproduct of an industry experiencing rapid growth or major innovation, and telehealth continues to see movement in both each year.

Compound the lack of industry standards with the number of active players in the industry and one can quickly note a surmountable barrier for telehealth programs, initiatives, and companies to overcome. ${ }^{6}$ Specifically, the confusion caused by laws and regulations presents to telehealth programs, initiatives, and companies in the form of general knowledge needed to appropriately utilize telehealth codes and comply with payer 


\section{Table 1. Telehealth finance variables and definitions}

\section{Telehealth}

finance variables

Fee-for-service

(FFS) payments
- Reimbursement (payment) for a telehealth service based on a determined or negotiated fee schedule that is not linked to quality of the patient care delivered or a desired patient outcome. The fee is paid if and how often the service is delivered and is centered around the volume of the service delivered. Growing the service increases revenue with no correlated connection to patient and provider satisfaction or quality and outcomes. The healthcare industry is moving away from fee-for-service reimbursement models. Numerous payers in the healthcare industry and varying state-specific telehealth laws and regulations create a widely varied range of fees and services covered, creating inconsistency for tracking and reporting by telehealth programs, initiatives, and companies. Common fee-for-service payers includes Medicare, State Medicaid, Private Payers, and Self Pay.

Value-based payments

- Reimbursement (payment) for a telehealth service dependent on the cost, efficiency, quality, and outcome. The fee is paid if and how the service is deemed to be of value to the patient, system, or payer and is centered around the quadruple aim of cost, quality, access, and improving the work life of clinicians and staff. ${ }^{3}$ Telehealth can be a cornerstone of value-based payments, as it can maximize access to care in an efficient manner. However, exact financial costs associated with value-based payments are not standardized in the industry; therefore, assigning a financial value to telehealth as part of a value-based payment is varied or continuously measured until transparently defined by the telehealth program, initiative, or company.

Per member per

- Reimbursement (payment) for a telehealth service that is associated with the month or per patient per month ongoing availability of a service to a member, patient, or group of patients or as part of an extended care plan where care is delivered on a regular basis at least once a month or more. Per member per month reimbursement is common among telehealth programs that utilize the Centers for Medicare and Medicaid Services (CMS)/Medicare Chronic Condition Management (CCM), Transitional Care Management (TCM), and Remote Patient Monitoring (RPM) codes and reimbursement. One example is using a RPM initiative that reimburses the hospital per patient per month and helps that patient by keeping him or her away from coming back to the hospital in less than 30 days. The revenue and savings in this example are both direct and indirect in how it presents to the hospital or health system. Per member per month reimbursement is also common among telehealth companies that offer large and small employer groups access to a telehealth consult service.

Coinsurance service or a determined or negotiated fee schedule based on a service category.

Continued 
Table 1 (Continued). Telehealth finance variables and definitions

\begin{tabular}{|c|c|}
\hline $\begin{array}{l}\text { Telehealth } \\
\text { finance variables }\end{array}$ & Definition \\
\hline Shared savings & $\begin{array}{l}\text { - Reimbursement (payment) as part of a determined or negotiated outcome or quality } \\
\text { benchmark being achieved for a defined population through a telehealth service and } \\
\text { can be reimbursed on a rolling or set schedule (often quarterly or annually). One } \\
\text { party agrees to pay a telehealth program, initiative, or company an agreed-upon } \\
\text { payment at a particular quality benchmark or expected outcome. Achieving the } \\
\text { quality benchmark or expected outcome saves a party an expected cost and they in } \\
\text { turn pay the telehealth program, initiative, or company a portion of that cost savings. }\end{array}$ \\
\hline $\begin{array}{l}\text { Reduced } \\
\text { readmissions }\end{array}$ & $\begin{array}{l}\text { Avoidance of readmitting patients to a hospital in less than } 30 \text { days utilizing } \\
\text { a telehealth program, service, or company. Hospitals and health systems are } \\
\text { subjected to losing their collected revenue for an inpatient Medicare stay if that } \\
\text { patient returns to any hospital and is readmitted for any reason in } 30 \text { or less than } \\
30 \text { days. The loss of revenue associated with these patients on an annual cycle } \\
\text { can be significant and jeopardize the entire health system or hospital's financial } \\
\text { viability. Utilization of a telehealth program, service, or company to work with } \\
\text { at-risk patients and populations can reduce this annual cost and be a measurable } \\
\text { savings for the hospital or health system. }\end{array}$ \\
\hline $\begin{array}{l}\text { Patient } \\
\text { satisfaction }\end{array}$ & $\begin{array}{l}\text { Satisfaction a patient has with a telehealth service, initiative, or company. } \\
\text { Telehealth services are convenient, centered around the patient, and improve the } \\
\text { access to a range of specialists. Measuring the satisfaction of a telehealth patient } \\
\text { and the correlated financial benefit for both the patient and the health system is a } \\
\text { continuous variable to note, although complex to define a standard. }\end{array}$ \\
\hline $\begin{array}{l}\text { Avoidable } \\
\text { patient days }\end{array}$ & $\begin{array}{l}\text { The difference in the count of days a patient has in an inpatient setting if he or she } \\
\text { has access to a qualified specialist provided via a telehealth service, initiative, or } \\
\text { company compared to not having that access. Having timely and efficient access } \\
\text { to services, such as neurology and psychiatry consults as an example, can result } \\
\text { in the reduction of avoidable patient days, creating a cost saving for the hospital. }{ }^{4}\end{array}$ \\
\hline $\begin{array}{l}\text { Avoidable visits } \\
\text { to emergency } \\
\text { department }\end{array}$ & $\begin{array}{l}\text { - The count of visits an emergency department has for patients who did not have } \\
\text { emergent needs for care. The presence of a telehealth program, initiative, or company } \\
\text { can reduce avoidable visits to the emergency department by giving patients a } \\
\text { convenient and accessible option to receive care by a qualified medical professional. } \\
\text { The overall rising cost of healthcare can be combated by providing the right care, at } \\
\text { the right time, in the right care setting by a telehealth program, initiative, or company. }\end{array}$ \\
\hline $\begin{array}{l}\text { Provider time } \\
\text { (efficiency) }\end{array}$ & $\begin{array}{l}\text { The time a provider spends with a patient as part of a telehealth program, initiative, } \\
\text { or company. Depending on a hospital's or health system's regional facilities, providers } \\
\text { who use telehealth may experience an increase in time spent with patients due to a } \\
\text { decrease in need to drive to multiple sites to see patients. Maximizing provider time } \\
\text { with clinical care as part of a telehealth program, initiative, or company can make } \\
\text { providers more efficient part of a well-designed and managed business model. }\end{array}$ \\
\hline
\end{tabular}

Continued 
Table 1 (Continued). Telehealth finance variables and definitions

\begin{tabular}{|c|c|}
\hline $\begin{array}{l}\text { Telehealth } \\
\text { finance variables }\end{array}$ & Definition \\
\hline $\begin{array}{l}\text { Capacity } \\
\text { and resource } \\
\text { utilization }\end{array}$ & $\begin{array}{l}\text { The capacity and utilization of resources or assets associated with a telehealth } \\
\text { program, initiative, or company. The hardware and software associated with } \\
\text { telehealth programs, initiatives, and companies have a cost. Tracking that cost } \\
\text { with the utilization ensures that this continuous variable can be optimized and } \\
\text { allocated accurately against monthly, quarterly, and annual budgets. }\end{array}$ \\
\hline $\begin{array}{l}\text { Total cost of care } \\
\text { and quality of } \\
\text { care }\end{array}$ & $\begin{array}{l}\text { A patient's total or episodic cost of care associated with a telehealth program, } \\
\text { initiative, or company when compared to the total cost of care associated with } \\
\text { comparative in-person care. Evaluating the quality of care and patient outcomes } \\
\text { associated with a telehealth program, initiative, or company with the patient's } \\
\text { in-person care is important to determine ongoing value and sustainability of } \\
\text { telehealth programs, initiatives, or companies. }\end{array}$ \\
\hline $\begin{array}{l}\text { Downstream } \\
\text { referral revenue }\end{array}$ & $\begin{array}{l}\text { The referrals and associated revenue that can accompany a telehealth program, } \\
\text { initiative, or company. A telehealth program, initiative, or company is often } \\
\text { establishing a market presence (either online or through a remote or affiliate } \\
\text { clinic or hospital site) in an area or region that is new to them. In addition to the } \\
\text { patients served directly through a telehealth program, initiative, or company, } \\
\text { those patients may continue to seek additional in-person services or additional } \\
\text { online services. Without the presence and initial access promulgated by the } \\
\text { telehealth program, initiative, or company, the downstream referrals and an } \\
\text { increase in services from patients in that region would not have been realized. }\end{array}$ \\
\hline $\begin{array}{l}\text { Downstream } \\
\text { ancillary revenue }\end{array}$ & $\begin{array}{l}\text { Ancillary revenue (imaging, drugs, hospital admissions revenue, and } \\
\text { reduced transfers revenue) that can accompany a telehealth program, initiative, } \\
\text { or company. A telehealth program, initiative, or company is often providing } \\
\text { a specialty provider not traditionally present or accessible. The new presence } \\
\text { of a specialist provider due to a telehealth program, initiative, or company } \\
\text { can increase the ancillary revenue of an inpatient unit, emergency department, } \\
\text { or clinic. } \\
\text { For example, a rural hospital does not have a neurologist on its medical staff } \\
\text { due to recruiting or cost challenges; therefore, it implements a telestroke } \\
\text { program. Once the hospital has a telestroke program, it can adequately care } \\
\text { for a patient who arrives with a stroke instead of immediately stabilizing and } \\
\text { transferring. The hospital accesses a neurology consult via telehealth and } \\
\text { often the neurologist will order a CT scan and if appropriate, the drug, tissue } \\
\text { plasminogen activator (tPA), will be administered and the patient may be } \\
\text { admitted. Now as an inpatient, rounding on the patient will occur virtually for the } \\
\text { duration of the patient's hospital stay. }\end{array}$ \\
\hline
\end{tabular}

Continued 
Table 1 (Continued). Telehealth finance variables and definitions

\begin{tabular}{|c|c|}
\hline $\begin{array}{l}\text { Telehealth } \\
\text { finance variables }\end{array}$ & Definition \\
\hline & $\begin{array}{l}\text { - Each of those events is generating revenue for the hospital. Contrast that example } \\
\text { with a scenario where the hospital has no neurology coverage; in this case, the } \\
\text { hospital could have been completely bypassed by emergency medical services } \\
\text { and taken to a more capable hospital; or the patient would have arrived, only to be } \\
\text { stabilized and transferred to the more capable hospital. The downstream ancillary } \\
\text { revenue generated through a telehealth program, initiative, or company can be tracked } \\
\text { and reported as part of a successful business model, and is a value-driven continuous } \\
\text { variable as it facilitates the right care given at the right time in the right care setting. }\end{array}$ \\
\hline Facility fees & $\begin{array}{l}\text { - Reimbursement (payment) when a telehealth patient presents to a qualifying } \\
\text { healthcare site. There is a code (Q3014) that can be utilized by the qualifying } \\
\text { sites and it is recognized by public and private payers. Successful telehealth } \\
\text { business models leverage this reimbursement within their network despite the } \\
\text { low amount of associated reimbursement per encounter. }\end{array}$ \\
\hline $\begin{array}{l}\text { Extramural } \\
\text { funding }\end{array}$ & $\begin{array}{l}\text { Defined as the extramural or outside funding to a telehealth program, initiative, } \\
\text { or company: extramural funding is common among telehealth programs, } \\
\text { initiatives, and companies and presents from various sources and motives. } \\
\text { Extramural funding sources can include federal grant programs, federal } \\
\text { pilot and demonstration programs (CMS, Agency for Healthcare Research } \\
\text { and Quality, Health Resources and Services Administration, United States } \\
\text { Department of Agriculture, and National Institutes of Health), state-sponsored } \\
\text { legislative initiatives (South Carolina, Mississippi, Florida, and North Carolina), } \\
\text { private or endowment grant programs, and venture capital or private equity } \\
\text { investment. Federal, state, and private or endowment-centered grant programs are } \\
\text { designed to assist with the start-up and launch cost of a telehealth program, often } \\
\text { targeting regional areas with identified healthcare provider and access needs. } \\
\text { Since its inception in 1995, the USDA Distance Learning and Telehealth Grant } \\
\text { has funded numerous programs across the United States and territories. Venture } \\
\text { capital and private equity investment into telehealth has increased over the years } \\
\text { since the late 1990s, often targeting high-growth potential companies with a } \\
\text { vision to improve healthcare on a regional and global scale. A key similarity } \\
\text { of the types of extramural funding is that in every situation, predetermined } \\
\text { or negotiated plans and expectations are set with clear accountabilities and } \\
\text { responsibilities to be achieved by the involved stakeholders. A key difference of } \\
\text { the types of extramural funding is the element of generating sales or value on the } \\
\text { side of venture capital and private equity investment, whereas grant and federal } \\
\text { funding often require reporting on the achieved healthcare access and clinical } \\
\text { results or outcomes. Successful telehealth business models will seek and compete } \\
\text { for extramural funding as appropriate and when it aligns with the mission, vision, } \\
\text { and values of the telehealth program, initiative, or company. }\end{array}$ \\
\hline
\end{tabular}


requirements for billing and reimbursement. A lack of knowledge and comfort navigating the payer landscape is concerning for telehealth programs, initiatives, and companies for several notable compliance and financial sustainability reasons:

- Improper documentation for telehealth services

- Improper payments for telehealth services

- Missed opportunities to collect revenue

- Missed opportunities for cost savings

In 2016, Medicare paid a total of $\$ 28,748,210$ for telehealth services for a total of 496,396 claims. This includes payments to distant site providers and originating site payments. Compare this amount to the previous year (2015), in which Medicare paid a total of $\$ 22,449,968$ for telehealth services for a total of 372,518 claims. ${ }^{7}$ Note that the figures are slightly different than reported in prior years as the Centers for Medicare and Medicaid Services (CMS) changed its data collection and calculation methodology.

The change from 2015 to 2016 realized a 33\% increase in the number of Medicare telehealth claims submitted and a $28 \%$ increase in total payments. This uptick in total payments is not attributed to fee schedule rate increases, but rather to more providers using telehealth services with their traditional Medicare fee-for-services (FFS) beneficiaries. ${ }^{8}$

The major increases in utilization and submission of telehealth claims during the last few years, and notable increases from 2015 to 2016, show a trend expected to continue. The Office of Inspector General (OIG) and the CMS announced in the fall of 2016 that due to the significant increase in claims and payments in 2016, they would be actively auditing programs for compliant operations in 2018 and moving forward. ${ }^{8}$ Early 2018 brought the first glimpse of activity from the OIG and CMS when they announced that they had completed early internal audits on paid claims and found that of 100 audited claims, 31 were identified as non-compliant and against federal and/or state regulations. ${ }^{9}$ A breakdown of the audit showed the following: there were 191,118 Medicare paid distant-site telehealth claims, totaling \$13.8 million, which did not have corresponding originating-site claims. We reviewed provider supporting documentation for a stratified random sample of 100 claims to determine whether services were allowable in accordance with Medicare requirements.

CMS paid practitioners for some telehealth claims associated with services that did not meet Medicare requirements. For 69 of the 100 claims in our sample, telehealth services met requirements. However, for the remaining 31 claims, services did not meet requirements. Specifically:

- Twenty-four claims were unallowable because the beneficiaries received services at nonrural originating sites.

- Seven claims were billed by ineligible institutional providers.

- Three claims were for services provided to beneficiaries at unauthorized originating sites.

- Two claims were for services provided by an unallowable means of communication.

- One claim was for a noncovered service.

- One claim was for services provided by a physician located outside the United States.

We estimated that Medicare could have saved approximately $\$ 3.7$ million during our audit period if practitioners had provided telehealth services in accordance with Medicare requirements. 
The key federal and state requirements to note for telehealth billing and reimbursement include, but are not limited to, the following:

- Medicaid utilizes Medicare eligibility in most covered providers and services, but some differences do exist; ensure a full review has been done to confirm similarities and differences

- Eligible providers

- Eligible services

- Eligible locations, sites of service (geography)

- Covered codes from CMS

- P02 (telehealth place of service indicator)

- 2019 Legislation federally and by each state

- Commercial payer contracting and negotiating (state or nationally applicable)

\section{SUCCESSFUL TELEHEALTH BUSINESS MODELS}

A successful business model for a telehealth program, initiative, or company begins with the knowledge of financial variables and ends with a symphony of organized and efficient operations. A successful telehealth business model will demonstrate the attributes listed in Table 2.

Telehealth business models are an ongoing evolution in the healthcare industry, and the most prevalent and successful business models will identify with one of the following eight business models or arrangements (Table 3 ).

Additional telehealth program, initiative, and company business models will continue to emerge as the industry evolves. Every telehealth business model has some degree of patient care involved, and it is important to keep the seven attributes of successful telehealth business models in mind when interacting with telehealth. Each telehealth business model can benefit from having a clear and defined contract of all terms and responsibilities of each party involved. The negotiation, drafting, and execution process of clear and defined telehealth contracts is

Table 2. Attributes for a successful telehealth business model

\begin{tabular}{ll} 
1. Safe & $\begin{array}{l}\text { Care is equal to or better than traditional in-person care for the use case/clinical } \\
\text { service. }\end{array}$ \\
\hline $\begin{array}{l}\text { 2. Appropriate for } \\
\text { the patient's needs }\end{array}$ & $\begin{array}{l}\text { When evaluating clinical outcomes and designing the mode of telehealth, } \\
\text { a patient's interaction is important to contemplate. }\end{array}$ \\
\hline 3. Patient-centered & $\begin{array}{l}\text { Care and services provided are focused on the patient's needs during and after } \\
\text { the visit concludes. }\end{array}$ \\
\hline 4. User-friendly & $\begin{array}{l}\text { Patients, providers, and caregivers can easily navigate the hardware, software, } \\
\text { and interfaces involved before, during, and after the visit concludes. }\end{array}$ \\
\hline $\begin{array}{l}\text { 5. Compliant } \\
\text { 6. Mission driven/ } \\
\text { strategically aligned }\end{array}$ & $\begin{array}{l}\text { The telehealth program, initiative, or company and the care and providers } \\
\text { involved are meeting all federal and state laws and regulations. }\end{array}$ \\
$\begin{array}{l}\text { Kefined, tracked, and aligned within the telehealth program, initiative, or a } \\
\text { company's ownership and operations. }\end{array}$
\end{tabular}




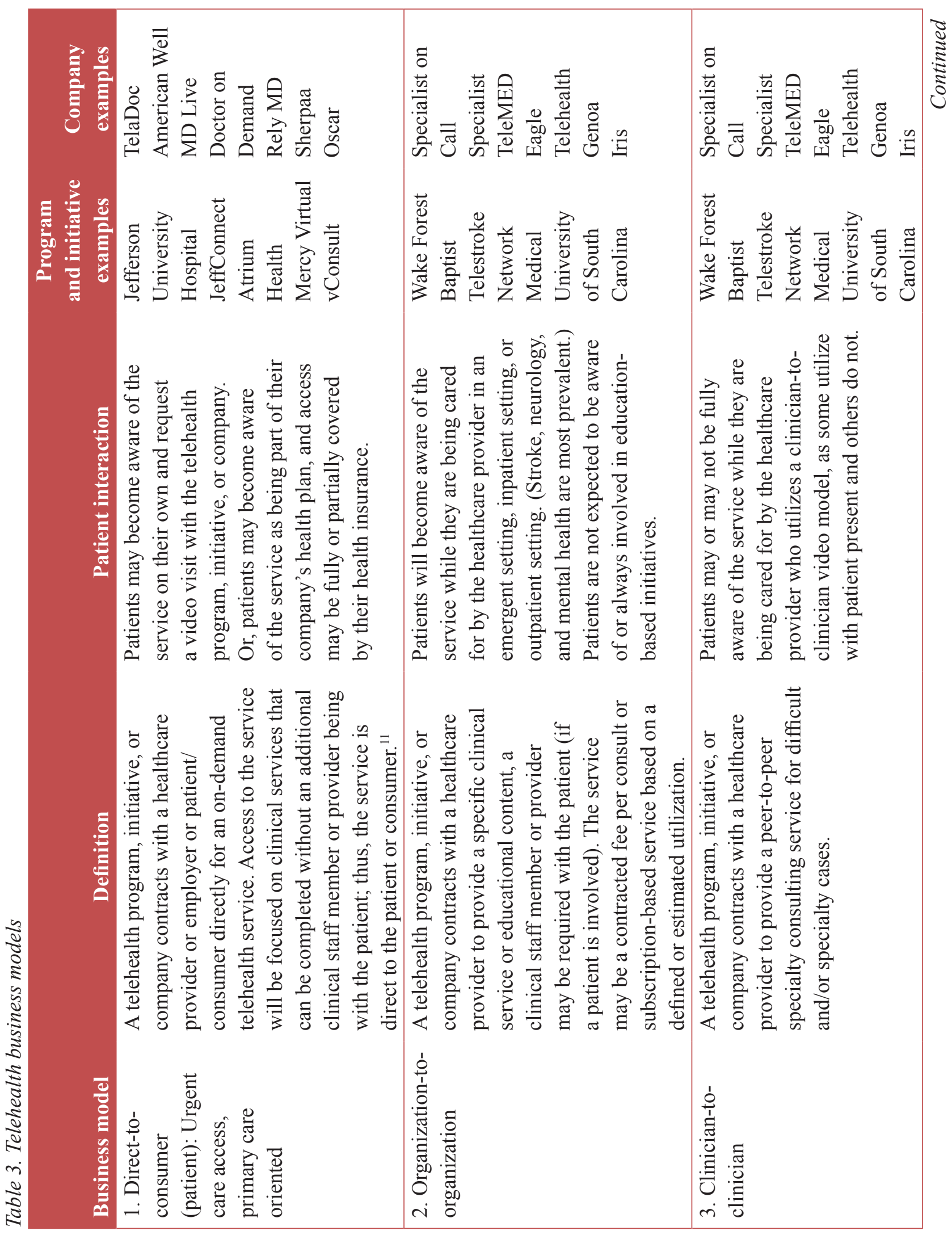




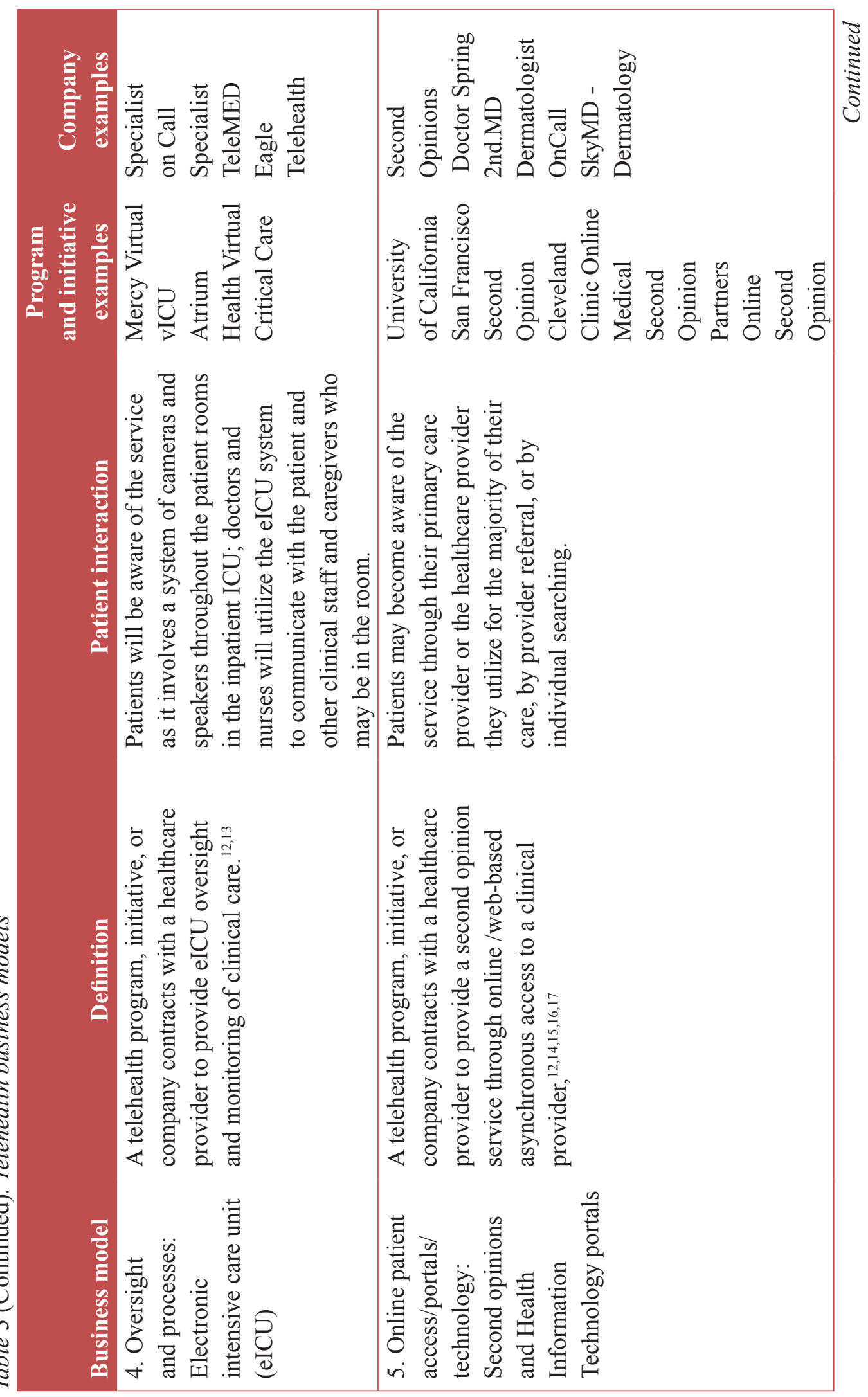




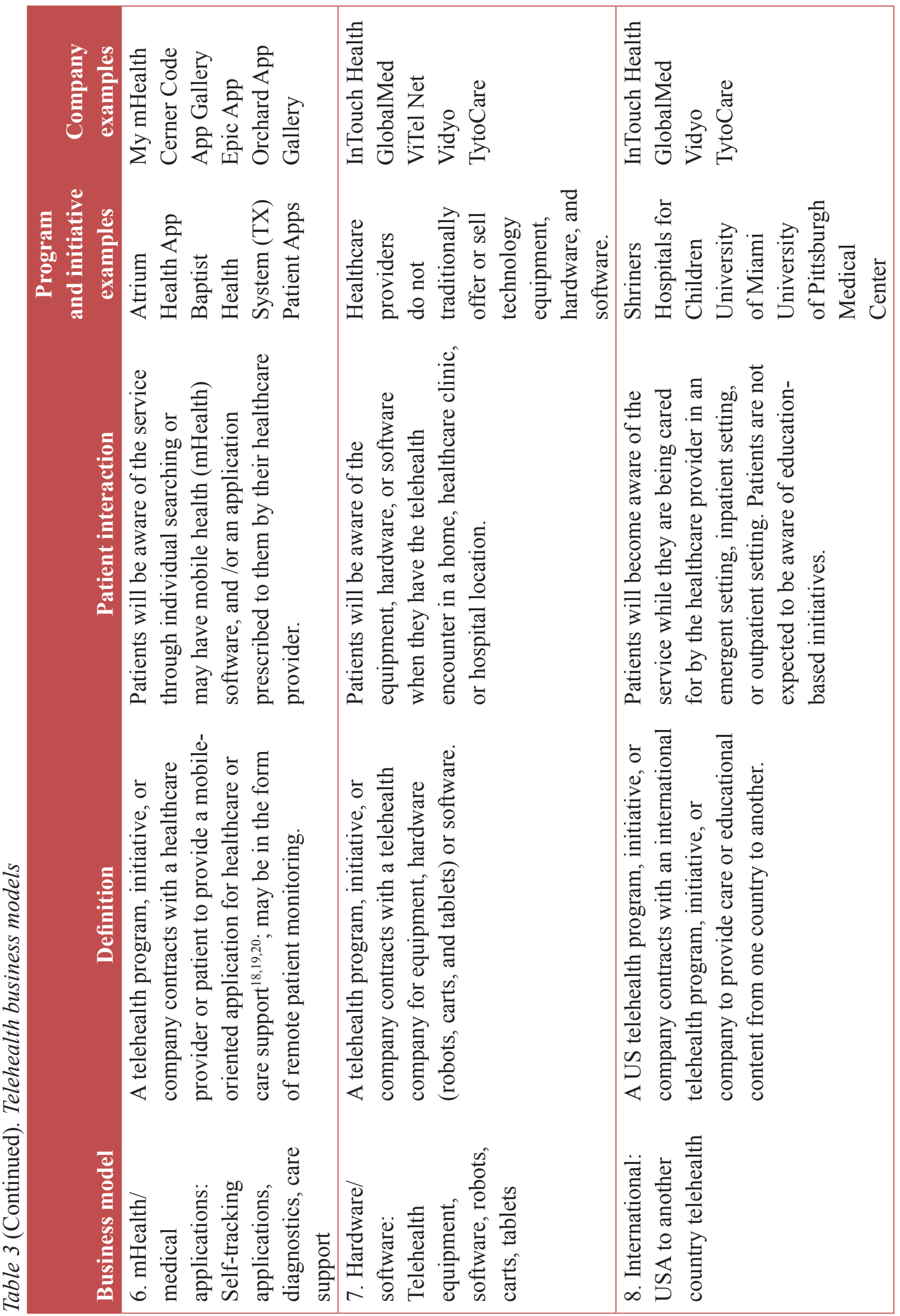


an important cornerstone of success when designing and operating a successful telehealth business model.

\section{RETURN ON INVESTMENT AND VALUE ON INVESTMENT}

Universal adoption of telehealth continues to lag despite improved technology and increasing amounts of evidence demonstrating effectiveness. Two key reasons for historically lagging adoption include ${ }^{21}$ :

1. Complexity of policy at both federal and state levels related to reimbursement for telehealth services

2. The fragmented approach that organizations are using to forecast ROI, creating a bleak picture of financial returns and thus program feasibility

Traditional business models within healthcare focus on direct revenue gained primarily through FFS reimbursement. A telehealth program's, initiative's, or company's approach of considering traditional, FFS reimbursement as the dominant input to ROI is flawed in the sense that it excludes some of the key benefits and underlying value of telehealth program, such as cost, quality, efficiency, and access, which will be referred to in this article as VOI. Unlike traditional ROI models, financial benefits in healthcare also come in the form of cost avoidance and downstream revenue opportunities. Telehealth programs, initiatives, or companies will need to deploy varied methods and approaches to estimate telehealth ROI, thinking more broadly in terms of how telehealth functions as an asset to a program, initiative, or company by generating value in the form of cost savings, increased efficiency, and downstream revenue opportunity.

Deploying varied methods and approaches to analyzing telehealth ROI and VOI will require creating business models within frameworks that include a variety of financial inputs. The use of a variety of financial inputs will generate a more complete picture of all financial gains and cost savings associated with telehealth efforts. The nuances and challenges of measuring ROI and VOI, and the evolving field of health economics, is such a popular topic that it prompted the organization of the 2016 Global Health Economics Consortium Colloquium co-sponsored by leading researchers and faculty at Stanford Health Policy, UCSF Global Health Sciences, and the UC Berkeley School of Public Health. ${ }^{22}$

A DEPARTURE FROM VOLUME TO VALUE Traditionally, the business case for a telehealth program, initiative, or company is based on FFS revenue collected from insurers or patients and viewed as the key input to project ROI. As the landscape of healthcare transitions from volume and direct revenue to quality, access, and cost, the need to adapt financial practices estimating return and value associated must evolve.

Traditional ROI can be thought of as the gain from the investment, or revenue, minus the cost of the investment, which yields net profit, divided by the cost of the investment:

$$
\begin{gathered}
\text { Traditional ROI }=(\text { Total Revenue }- \text { Total Cost }) \\
\text { or Net profit/Total Cost }
\end{gathered}
$$

The problem with this calculation in today's evolving healthcare environment is that the "Total Revenue" input is driven by FFS, or volume-based, payments. Telehealth VOI must be thought of more broadly from a financial perspective to include all contributions translating to benefit for the organization. ROI is flexible and can be modified to support the industry or situation. In the case of healthcare, benefit (direct and indirect) is a key element 
of the ROI expression. What is included in the telehealth VOI will vary from organization to another and from one program to another and may include avoidable cost, shared savings, and referrals made back to the telehealth program, initiative, or company. VOI can be thought of as the gain from the investment, in terms of revenue (direct), cost savings (indirect), downstream revenue (indirect), and increased efficiencies (indirect), minus the cost of the investment, which yields net value, divided by the cost of the investment:

$$
\begin{gathered}
\mathrm{VOI}=(\text { Total Direct Revenue }+ \text { Total Indirect } \\
\text { Revenue or Cost Savings })- \text { Total Cost }
\end{gathered}
$$

\section{KEY CONCEPTS OF TELEHEALTH ROI AND VOI}

Defining a financial ROI for a telehealth service or program may require considering new inputs and variables that translate to returns in the form of value, or VOI, yielding benefit and goodwill that can be translated to financial realization, in addition to profits. Some of the core intangible benefits that may translate to returns in the form of VOI include:

- Eliminates geographical boundaries to leverage distributed clinical expertise and capacity

- Improves quality of life for the patient and family

- Enables opportunities to further extend care to new market areas and international locations

- Provides new collaboration methods to enable new partnerships

- Improves the ability to collaborate among physicians, departments, locations, and services to make more informed patient care decisions and coordinated care delivery

- Provides opportunity to deliver care more efficiently and to better manage care transitions
One metaphorical approach to the process is to brainstorm financial inputs as one would view an iceberg. There will be inputs that are on or above the surface that translate directly to profits and can be quantified rather precisely, such as FFS revenue and copays. There will also be inputs that are below the surface that translate more indirectly and may be more difficult or less precisely quantified numerically, such as reduced readmissions, increased provider efficiency, and increased referrals to the system. It is common to define a mix of variables that can be broken apart, evaluated, and fit into a mix of complimentary financial levers that create a compelling business case. Figure 1 illustrates one example of the iceberg analogy used to project returns and value for a telehealth program, initiative, or company. ${ }^{23,24}$

The practice of building an ROI for telehealth is fluid and continuous, and associated inputs will likely evolve as the industry releases innovative programs, technologies, and ways of doing business. Direct Revenue Streams, referred to on the iceberg as "above the surface" may be revenue in the form of FFS, site of service facility fees or hospital billing, and direct-to-patient payments. If requirements are appropriately planned for and met, FFS revenue can be the least complex ROI input to forecast. A list of an exploration of "above the surface" inputs that may be a part of a telehealth program, initiative, or company includes fee for service (professional billing), site of service facility fee (hospital billing), direct-to-patient, and direct contracting.

\section{Fee-for-Service (Professional Billing)}

This describes reimbursement from eligible telehealth codes with affixed modifiers, such as GT, GQ, or 95, for furnished telehealth services. Professional or FFS payments within telehealth must meet the rules and requirements of payers. 


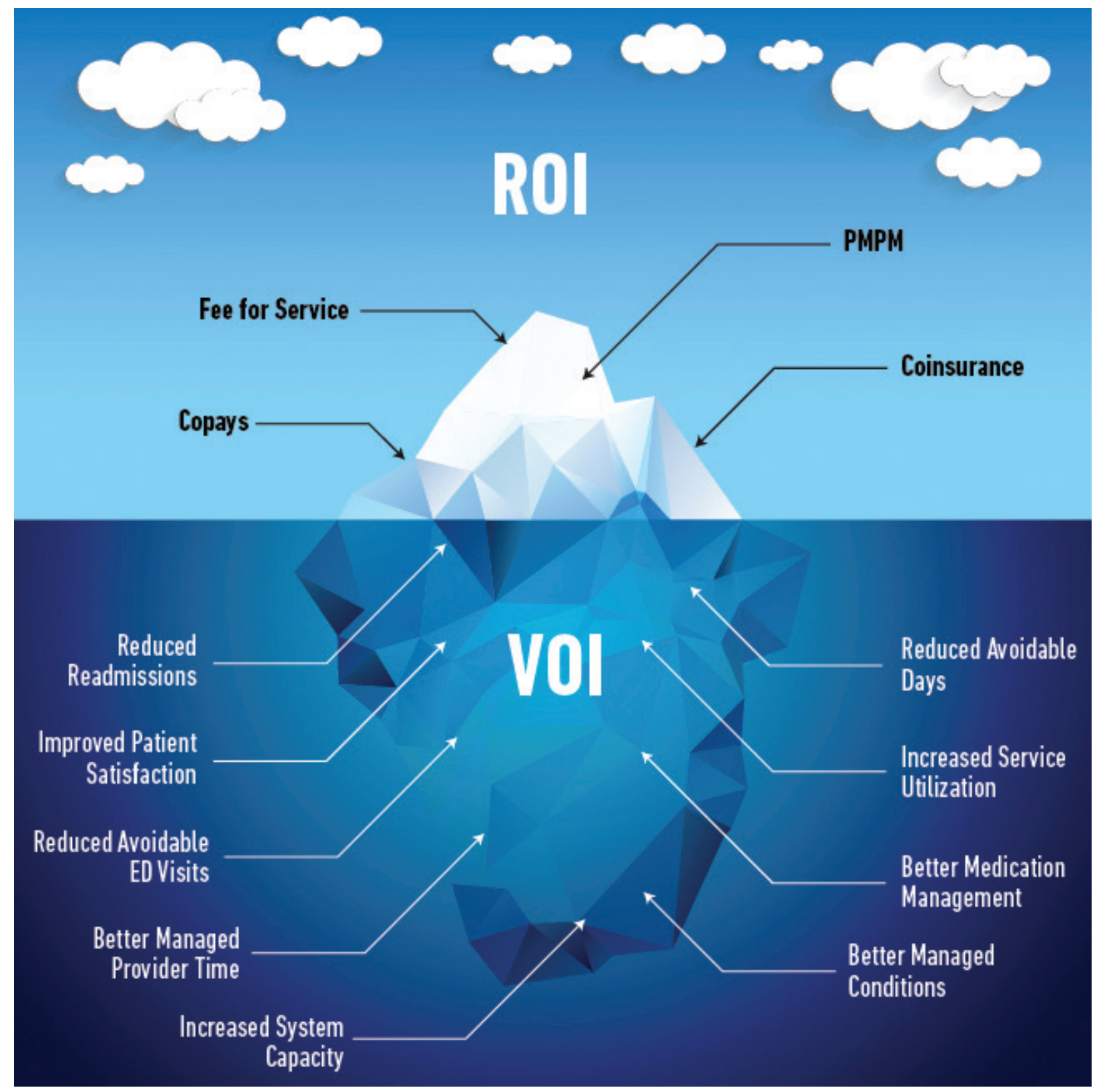

Figure 1-Exploring "above the surface" inputs.

As of 2018, Medicare reimburses for 97 different Common Procedural Technology (CPT codes) and Healthcare Common Procedure Coding System (HCPCS) codes, at an average rate of \$115-\$125 per code, with Medicaid and private payers in many states matching or exceeding that number of covered codes. To be eligible for payment and in compliance with payer requirements, programs, initiatives, and services should consult insurer policies for telehealth reimbursement. The landscape continues to evolve and become more favorable to payment; however, many payers still have conditions for payment related to rurality, providers, documentation, and services. In 2019, Medicare, which is one of the more restrictive payers for telehealth services, will lift the geographic restriction for payment of 
telehealth services for telestroke, which is a strong favorable signal to the industry. ${ }^{25}$

\section{Site of Service Facility Fee (Hospital Billing)}

This is a reimbursement paid to the site where the patient is located during the time of telehealth service. It is known within Medicare as the originating site facility fee and identified by eligible code Q3014 by many payers.

Facility fee payments range from $\$ 15$ to $\$ 40$ per encounter. If the site of service is part of a larger system or organization, this payment should be considered as part of the direct revenue stream of a telehealth program, initiative, or company. ${ }^{25}$ To obtain specific information on the eligible code and rate reimbursed, consult individual payer policies in the state in which your organization resides.

\section{Direct-to-Patient}

Also known as out of pocket or self-pay, directto-patient is defined as point-of-service payments from direct to consumer or Teleprimary programs. It could also be in the form of copayments and/or coinsurance. This form of payment is common in direct to consumer telehealth programs, initiatives, or companies, caring for primary and minor acute patients' needs. On average, a virtual primary care visit with a direct-to-patient fee will range between $\$ 50$ and $\$ 75$ per visit, for a secure, face-to-face video encounter for primary care needs.

\section{Direct Contracting}

A growing trend, direct contracting occurs when groups such as employers and insurers partner with a provider of telehealth services to receive payment according to a predefined contract. Direct contracting has been referenced by Snap MD CEO, Dave Skibinski, as a telehealth "Trojan Horse" due to the disruption of the natural flow of referrals that would typically occur within health systems now being directly contracted to vendors. ${ }^{26}$ Although the trend has been for telehealth service providers to adopt this business model, hospitals and health systems are many times in a position to also use this financial model. The contracted rate for services is largely dependent on the market and service being offered and may vary greatly from contract to contract.

\section{EXPLORING "BELOW THE SURFACE" INPUTS}

The practice of building a VOI for telehealth goes beyond "above the surface" inputs to draw synergies and net positive impact associated with cost savings and downstream revenue into the overall business case for telehealth initiatives, programs, and companies. Indirect revenue streams, referred to on the iceberg as "below the surface," are more difficult to measure and predict when projecting financial returns for telehealth programs and services; however, they are still a vital component of the total telehealth picture. Indirect revenue may come in the form of avoidable cost, economies of scale, quality, and patient satisfaction. Including indirect revenue as part of a telehealth financial model goes beyond return to estimate full VOI.

According to the eHealth Director, Pam Forducey ${ }^{27}$ :

\footnotetext{
Organizations across the globe are becoming creative in their approaches to estimating 'below the surface' impact to include as part of a program's VOI. For example, INTEGRIS Health, a self-insured provider, utilizes an advisory committee to evaluate prospective projects and services to work toward establishing metrics to track returns and value. Additionally, new projects require a business plan with a financial ROI and ongoing assessment of clinical and financial performance after launch.
} 
One example is reducing 30-day readmissions using home-based telehealth monitoring equipment. Another example is reducing travel expenses for physicians traveling across the state to provide regional outreach. Continued patient engagement is another ROI-particularly for patients who would otherwise not travel long distances for 15- to 20-minute follow-up visits. For the purposes of this article, we refer to indirect revenue stream inputs as the VOI component of a telehealth financial model. ${ }^{27}$

Each telehealth program or service will calculate indirect revenue a bit differently. Resources, such as case studies and benchmarks, are published frequently for a wide range of telehealth specialties and can serve as a starting point for estimating indirect cost savings or revenue generation as part of a telehealth ROI. For example, remote monitoring for chronic care management is an area of telehealth that demonstrates significant indirect revenue opportunity. A study by the Canadian Department of Health and Queens University found that a remote patient monitoring (RPM) program yielded the following results that can be translated into data points within a financial model (Table 4). ${ }^{24,28}$

Indirect revenue stream inputs that should be included to project full VOI within telehealth business cases typically fall into two categories:

Table 4. CPRP program highlights

\begin{tabular}{|ll|}
\hline $\begin{array}{l}\text { Totals } \\
\text { Patients enrolled (as of December 2017) }\end{array}$ & \multicolumn{1}{l}{$\mathbf{N}(\mathbf{\%})$} \\
Patients in evaluation (enrolled by June 2017) & 745 \\
\hline Retention (>3 months on program) & $650 / 745(87 \%)$ \\
\hline Devices & 1,922 \\
\hline Device readings & 368,510 \\
\hline Medical alerts & 28,703 (1 alert/12.8 readings) \\
\hline Paramedic-patient coaching interactions & 3,281 \\
\hline Benefits & \\
\hline 911 call reduction (Interdev) & $26 \%(453$ calls) \\
\hline $\begin{array}{l}\text { Time reallocated to paramedic services } \\
\text { Total savings to paramedic services }\end{array}$ & 764 hours \\
\hline $\begin{array}{l}\text { Actual reduction in ED transport (Interdev) } \\
\text { Actual reduction in ED visits (ICES) }\end{array}$ & $\$ 331,576$ \\
\hline Actual reduction in hospital admissions (ICES) & $31 \%(460$ transports) \\
\hline Actual reduction in hospital readmissions (ICES) & $26 \%(467$ ED visits) \\
\hline Estimated savings to overall health system (650 patients) & $32 \%(170$ admissions) \\
\hline Estimated cost to implement Community Paramedicine Remote & $35 \%(18,7$-day readmits) \\
Patient Monitoring (CPRPM) program & $\$ 1 \%(59,30$-day readmits) \\
(assuming 6-month program duration) & $\$ 4,731,350$ \\
\hline Estimated ROI to overall health system & $\$ 7,279 /$ patient \\
\hline
\end{tabular}


cost savings and revenue generating. Figure 2 displays an exploration of possible indirect inputs.

Examples of inputs which could yield cost savings as part of a telehealth program's overall VOI include the following.

- Reduced readmissions and avoided penalties

- Reduced hospital length of stay

- Increased patient or client satisfaction

- For example, in a recent survey, patients and families who utilized telehealth services felt that it was more convenient than a clinic visit, less disruptive to their life and routine, and they would choose to use it again (30).

- Increased quality of care

- Reduced overutilization (in shared savings models)

$\circ$ For example, one study ${ }^{4}$ found that in two instances of comparing telehealth with traditional, in-person care, a lower rate of hospitalization was reported ( 2.2 vs. 5.7 days annually per patient). Additionally, another study ${ }^{29}$ found that patients utilizing telehealth instead of traditional, in-person care had fewer hospitalizations, shorter length of stay, and fewer visits to the emergency department.

- Reduced no-shows for outpatient appointments

For example, a study found that patients who received telehealth were less likely to miss hemodialysis treatment sessions compared with patients receiving only standard care. ${ }^{4}$

- Better medication management

- Better complex condition management

- Shared shavings from Next Gen Accountable Care organizations

- Avoidable transport costs/miles saved

\section{Cost \\ Savings}

- Reduced readmissions and avoided penalties

- Reduced hospital length of stay

- Increased patient or client satisfaction

- Increased quality of care

- Reduced overutilization (in shared savings models)

- Reduced no shows

- Better medication management

- Better complex condition management

- Shared shavings from Next Gen ACO

Figure 2-An exploration of possible indirect inputs.

\section{Revenue Generating}

- Increased provider efficiency

- Increased utilization / referrals in service areas such as surgery, ancillary, other specialty services

- Increased retention rates

- Better access to the system

- New market share

- Goodwill 
- One program found that the average trip travel time from home to clinic was 6.8 hours. Due to the fact that a telehealth visit can avoid unnecessary travel time, it saves in transportation costs and time, which can be translated into an average of $\$ 486$ saved. ${ }^{30}$

Examples of inputs that could translate to incremental revenue as part of a telehealth program's overall VOI include the following:

- Increased provider efficiency

- Increased utilization/referrals in service areas such as surgery, ancillary, other specialty services

- Increased retention rates

- Better access to the system

- New market share

- Goodwill

\section{CHALLENGES TO ESTIMATING TELEHEALTH ROI AND VOI}

The promise of strong ROI and VOI for telehealth programs, initiatives, and companies comes with unique challenges that should be considered as part of any financial analysis or model. It is also important to consider that since healthcare is highly localized, the way in which one program, initiative, or company successfully defines and measures telehealth ROI is not necessarily the same that another will do. Challenges inherent in projecting returns and VOI in telehealth programs may also widely vary; however, some common issues across the industry include:

1. Complexities of the healthcare insurance market

2. Identifying and quantifying indirect revenue streams

3. Measurement and tracking of data in disparate systems
COMPLEXITIES OF THE HEALTH CARE INSURANCE MARKET

The reimbursement environment for telehealth by traditional insurance providers is both varied and complex. Policies and conditions for payment are quite restrictive today at the federal level. Due to the number of payers and the management of health insurance on a state-by-state basis, the industry is faced with no clear or universal way to determine direct payment for telehealth services. Rather, each individual insurance carrier is left to set policy requirements for themselves, leaving those looking to receive reimbursement to build the appropriate workflows within their programs, initiatives, and companies to satisfy an exponential number of rules.

\section{IDENTIFYING AND QUANTIFYING INDIRECT REVENUE STREAMS}

We have defined and reviewed the difficulty in measuring indirect streams of revenue. These difficulties can be due to several factors, including challenges identifying indirect variables that have financial impact, no historical data points to predict future and defining how to measure and monitor variables in a consistent, reliable way. The variables that create indirect impact may vary by the type of telehealth program or services being offered. A recent article by the Advisory Board has explored different motivations and metrics within telehealth programs that complement direct revenue and alternatively measure telehealth's effect on program performance, ${ }^{31}$ including real-time virtual visits, asynchronous store-and-forward, and RPM.

\section{Real-Time Virtual Visits: Protect and Diversify Your Brand}

Downstream referrals: Ideally, a real-time virtual visit platform does not only guide new patients into the system; it also spurs subsequent use of 
other in-network services. Downstream referral rate and corresponding revenue can measure platform contribution to brand loyalty.

Existing patient retention rates: Real-time virtual visits meet the consumer desire for accessible, on-demand care and may help retain current patients otherwise drawn by cost or convenience elsewhere. Existing patient retention rates assess whether virtual care prevents patient leakage, promoting long-term consumer engagement with the organization.

\section{Asynchronous Store-and-Forward: Enhance Efficiency}

Time-to-consult fulfillment: The more quickly providers reply and fulfill requests for care guidance, the greater the time savings.

To evaluate operational benefits for your asynchronous store-and-forward solution, benchmark the time duration between consult request and provider response against less dynamic platforms, such as telephone and in-person visits.

Diagnostic accuracy: Do not sacrifice quality for expediency. Measure diagnostic accuracy to ensure that your platform both promotes efficiency and consistently resolves presenting conditions.

\section{Remote Patient Monitoring: Manage Your Population Health Enterprise}

Readmissions rate: By remotely tracking patient status, providers can use RPM to intervene when necessary and avoid care escalation. Measure readmissions rate to evaluate how RPM program prevents penalties and keeps patients at home, freeing up bed space.

Patient adherence to treatment plan: Among patients with chronic conditions or those recovering from surgery, RPM platforms frequently include checklists and reminders to help patients follow care instructions. Tracking treatment adherence demonstrates how a program impacts health behavior and positions an organization for downstream cost savings.

\section{MEASUREMENT AND TRACKING WITHIN DISPARATE SYSTEMS}

Inputs to financial models may be housed in different systems that need to be integrated to determine the full picture of "value." This reality creates a challenge in the ongoing measurement and monitoring of variables necessary to develop ROI and VOI. Some of these inputs may be more easily measured and tracked than others; however, they still represent significant opportunity within the financial model of a telehealth program, initiative, or company. The telehealth ROI includes indirect and direct variables, and telehealth-specific data can be challenging to collect across different healthcare organization information systems (e.g., electronic health records, video servers, telehealth vendor platforms, remote home monitoring platforms, human resource [HR] systems, financial systems, and so on). It may be prudent to consider using automated software to facilitate rapid and ongoing tracking of telehealth ROI and VOI components.

\section{ACHIEVING SUCCESS WITH TELEHEALTH ROI: BEST PRACTICES}

Analysis of all telehealth financial variables is an exercise that telehealth programs, initiatives, or companies should complete in partnership with leadership, ultimately seeking approval of defined inputs to enable the continuous tracking of their ROI through an established governance structure. The fundamentals of effective telehealth governance are explored later in this article. Once established, the business case around a telehealth program, initiative, or company should be created to 
determine feasibility. Review quarterly reports of the strategic telehealth ROI scorecard across clinical, financial, operational, and technical areas. Telehealth ROIs are unique and complex for every organization according to the maturity of the telehealth program.

To understand how to model the mix of possible telehealth finance variables for the ROI, the program, organization, or company must understand what the variables are (metrics), define how they are measured (measure), and must track them on an ongoing basis (monitor). Leading healthcare organizations that regularly track and communicate effectiveness create and ensure a strong telehealth culture that grows across the organization.

Within the reimbursement environment, best practice organizations are navigating these challenges using five key success criteria to ensure compliant and optimized telehealth ROI processes (Table 5).

\section{OTHER FACTORS THAT IMPACT OR CONTRIBUTE TO ROI}

A telehealth program, initiative, or a company's ROI can be further strengthened by using formal planning that aligns with their organization's strategic priorities, well-executed marketing and education efforts, and focus on adoption of the model.

Strategic planning of telehealth programs to align project ROI to market drivers or reasons for starting the program is a key element to successful launch and operations, which will translate to the bottom line. Organizations that take the time to understand the unique needs of their customers and market are at an advantageous position than those that do not, which can greatly contribute to a program's financial health. Market drivers for telehealth may include the following:
- Shortage of providers and specialty care, particularly in rural or underserved areas

- Rising number of people needing care due to aging populations

- Changing reimbursement landscape focused on management across the continuum of health, rather than single episodes of care

- Shift in the way customers and patients are seeking care, where convenience is expected

- Smart-phone use and the way technology applications support our lifestyles

Along with intentional planning and strategic alignment, telehealth initiatives, programs, and companies need to consider how they could outreach and educate internal and external audiences about program offerings. Marketing and outreach efforts should go hand in hand with the implementation and ongoing operations of a new program or service. Formal orientation sessions are one way that organizations are reaching out to populations they serve to increase program utilization.

The University of Mississippi Medical Center (UMMC) conducted a pilot study, which identified commonalities among employees who took advantage of UMMC's corporate telehealth services. The study gleaned several key characteristics related to utilization of the corporate telehealth program by their employees. Interestingly, the study determined the highest utilization of the program by employees aged 30-49 years who also attended a formal orientation session. The orientation session was conducted by both the employer's human resources leadership and a UMMC corporate telehealth representative. A key takeaway from this study is that corporations seeking to adopt corporate telehealth services as an effective method to reduce overall healthcare costs and employee absenteeism may further benefit from including a required orientation to 
Table 5. Five key success criteria to ensure compliant and optimized telehealth ROI processes

\begin{tabular}{|c|c|}
\hline Factors & Criteria \\
\hline $\begin{array}{l}\text { Contracts/ } \\
\text { agreements }\end{array}$ & $\begin{array}{l}\text { - All entities (within the program, initiative, and company) providing telehealth } \\
\text { - services have a contract or agreement } \\
\text { - Agreements for those entities clarify all party's obligations } \\
\text { - Meet } 12 \text { standard contractual provisions for telehealth contracts }{ }^{32} \\
\text { - Providers are appropriately credentialed with payers for billing } \\
\text { - Arrangements capture the full scope of all party's billing/compensation obligations }\end{array}$ \\
\hline $\begin{array}{l}\text { Policy/ } \\
\text { regulatory }\end{array}$ & $\begin{array}{l}\text { - Up-to-date on billing and documentation requirements by payer } \\
\text { - Monitor changing regulations via frequent reviews } \\
\text { - Maintain compliance at all times with changing regulations/requirements } \\
\text { - Ability to quickly communicate } \\
\text { - Agile response to change } \\
\text { - Negotiate with payers to drive additional coverage }\end{array}$ \\
\hline $\begin{array}{l}\text { Standard } \\
\text { operating } \\
\text { procedures }\end{array}$ & $\begin{array}{l}\text { - Create a formal telehealth development life cycle } \\
\text { - Define new program start-up process steps } \\
\text { - Internal policy requiring new program contract or agreement } \\
\text { - Standardize approach to provisions } \\
\text { - Internal policy and/or supporting procedures that promote a centralized } \\
\text { - telehealth department }\end{array}$ \\
\hline $\begin{array}{l}\text { Workflow } \\
\text { design }\end{array}$ & $\begin{array}{l}\text { - Standardized clinical, technical, operational, and financial workflows } \\
\text { - Automated systems (e.g., build) } \\
\text { - Clear roles and accountability } \\
\text { - Use of smart tools and text to increase documentation efficiency } \\
\text { - Integrate requirements into processes and systems } \\
\text { - Continuous focus on ease of use for end-users }\end{array}$ \\
\hline $\begin{array}{l}\text { Oversight/ } \\
\text { reporting }\end{array}$ & $\begin{array}{l}\text { - Centralized program oversight } \\
\text { - Established and communicated program governance } \\
\text { - Real-time, automated data and reporting dashboards to drive utilization, } \\
\text { documentation accuracy, quality, and ROI } \\
\text { - Automated software to facilitate rapid and ongoing tracking of telehealth ROI/VOI } \\
\text { - Maximization of revenue opportunity } \\
\text { - Denials management process } \\
\text { - Full operational transparency }\end{array}$ \\
\hline
\end{tabular}

ROI/VOI: return on investment/value on investment.

the program, while also developing additional methods for outreaching and educating employees who would not otherwise seek out medical treatment. ${ }^{11}$ Table 6 , taken from
Edgerton et al., ${ }^{11}$ discusses the number of e-visits by the type of program orientation corporation, the number of e-visits per 100 enrollees per year, and the type of orientation. 
Table 6. The number of e-visits by type of program orientation 11

\begin{tabular}{|lcl|}
$\begin{array}{l}\text { E-visits by type of program } \\
\text { orientation corporation (N) }\end{array}$ & $\begin{array}{c}\text { E-visits/100 enrollees } \\
\text { per year (N) }\end{array}$ & \multicolumn{1}{c|}{\begin{tabular}{c} 
Type of orientation \\
\hline Banking (corp. 2)
\end{tabular}} \\
& 95 & $\begin{array}{l}\text { Orientation with human resources and } \\
\text { telehealth staff }\end{array}$ \\
\hline Manufacturing (corp. 1) & 63 & Formal orientation with telehealth staff \\
\hline Manufacturing (corp. 4) & 35 & Formal orientation with telehealth staff \\
\hline Manufacturing (corp. 7) & 22 & No formal orientation \\
\hline Manufacturing (corp. 8) & 15 & No formal orientation \\
\hline Education, postsecondary (corp. 3) & 15 & No formal orientation \\
\hline Education, public, K-12 (corp. 9) & 12 & No formal orientation \\
\hline Planning and development (corp. 5) & 9 & No formal orientation \\
\hline Education, private, K-12 (corp. 6) & 7 & No formal orientation \\
\hline
\end{tabular}

Beyond formal education about program offerings, acceptance of technology is a key concern across the industry. Society continues to increase the use of and reliance on video and mobile technologies. The acceptance and growth of telehealth follows that same trajectory; however, it is important to anticipate and understand how to overcome existing barriers to adoption, particularly technology. Managerial principles, such as organizational structure, governance, well-defined workflows, and adherence to regulation and policy, play an important role in technology acceptance by end users, customers, and patients.

Drawing from the Technology Acceptance Model (TAM), which describes how user acceptance affects patients and clinicians in the journey toward abandoning more traditional methods for new technology and innovative approaches, two of the key drivers of technology acceptance within the TAM framework include the following:

1. How the innovative method or technology is diffused into the company, program, or initiative?
2. How the environment is configured to support the use of the technology?

Both drivers of TAM require defined governance and management support to be successful. Additional operational factors - such as clinical workflow, regulation, technical workflows, security, and financial workflow-will play an important role in the decision to purchase, implement, and adopt a technology.

According to Molfenter et al., existing technology adoption research has discovered that many factors can affect decisions to adopt and continue to use a technology. ${ }^{33}$ At the individual level, the TAM describes how user acceptance affects patients' and clinicians' willingness to abandon traditional practices in favor of new technologies. ${ }^{13,14,15}$ Beyond the individual level, explanatory models of organizational decisions to adopt a technology have emerged based on two prominent frameworks: diffusion of innovations and the technology-organizationenvironment framework. ${ }^{16}$ These models describe the fundamental role of management support and how factors such as clinical workflow, regulatory policy prohibiting and facilitating use concerns 
regarding information security, and financial/ reimbursement policy toward the technology affect the decision to purchase, implement, and use a technology. ${ }^{28}$

The role of leadership and their support and practice innovation in technology adoption will also play a major role in laying the foundation for success within the TAM. Teamwork and cooperation of line-level staff and program management will further drive the adoption of certain technologies. It will be vital to continue to activate these roles as future research on interventions in technology adoption is explored and implemented. ${ }^{33}$

\section{TELEHEALTH GOVERNANCE AND THE HEALTH SYSTEM INVESTMENT}

Telehealth governance is defined as the management structure for advancing a telehealth strategy by ensuring that the telehealth program, initiative, or company has the intentional leadership and investment to achieve an expected performance level or business model expectation.

Establishing governance is an essential first step toward reaching a consensus on how best to define, track, and organize the telehealth financial variables for a successful business model. Inherent to a successful telehealth business model is strong governance with a responsibility and accountability of intentional leadership focused on three key functions: management, prioritization of services, and achieving ROI or VOI. ${ }^{34}$

Focusing first on management, it is integral to demonstrate telehealth leadership capability in the following ways:

- Telehealth leadership provides the stakeholders of the telehealth program, initiative, or company timely, thorough, relevant, and accurate information about the telehealth industry.
- Telehealth leadership provides the stakeholders of the telehealth program, initiative, or company information regarding the market in which it operates, and how its strategies and operations support and strengthen the overall strategic and financial plans.

Telehealth leadership is most recognizable industry-wide in the form of a telehealth executive champion and a primary telehealth leader. Telehealth executive champions are identified by individuals serving in existing senior leadership roles, including but not limited to, chief information officer (CIO), chief technology officer, chief executive officer, chief operating officer, chief medical officer, chief medical information officer, and chief human resources officer. Telehealth leaders are identified by individuals serving in leadership roles, including, but not limited to, senior vice president (VP), chief telehealth officer, VP, executive director or director, telehealth, medical director, administrator, manager, and coordinator.

Telehealth organizational structures are necessary to support the telehealth leader and telehealth executive champions to achieve a successful telehealth business model. A top priority of the telehealth executive champion and the telehealth leader is the formation of a multidisciplinary team of clinical and administrative leaders to serve on an executive and/or steering committee for telehealth. An example of the departments represented on a telehealth executive and/or steering committee includes ${ }^{34}$ :

- Business Development

- Clinical Engineering/Biomedical

- Clinical Operations

- Compliance/Risk Management

- Employee Health

- Finance 
- Innovation

- Information technology/information systems (IT/IS)

- Legal

- Marketing

- Medical Staff/Medical Affairs

- Nursing

- Philanthropy

- Population Health

- Quality

- Revenue Cycle

A multidisciplinary telehealth executive and/or steering committee will execute the following responsibilities:

- Establish policies and procedures for developing, operating, recruiting, and compensating all key telehealth stakeholders involved. This includes, but is not limited to:

- Clinical providers

- Full and part-time support staff

- Medical director leadership dedicated to telehealth

- Evaluate key performance indicator dashboards of actual results against plans according to operations and clinical, technical, and financial goals

Telehealth governance effectiveness can be evaluated by assessing seven key requirements of the multidisciplinary telehealth executive and/or steering committee (as directed by the telehealth leader and telehealth executive champion, ${ }^{34}$ derived from White and Griffith's Well-Managed Healthcare Organization).

1. Meet legal requirements (licensing across state and international lines, credentialing at facilities and payers, coding, billing, reimbursement, hardware and software, security, CMS, Joint Commission on Accreditation of Healthcare Organizations
(JCAHO), and state/country-specific

departments of health and human services

2. Compliance, policies, and procedures that back up and align with legal requirements

3. Continuing education

4. Use of dashboards and automated data tracking

5. Culture

6. Conflicts of interest

7. Telehealth ROI performance (i.e., clinical, operational, financial, and technical)

Health System Investment is a direct byproduct of intentional leadership and telehealth governance. The investment is in the leadership and organizational structure (Figures 3 and 4) to fund and finance programs, strategies, and operating budgets. The organizational structure is one in which all departments of telehealth programs report to the Center for Telehealth Director and the VP of Operations. (e.g., mediumsized eight hospital health system in the Southeast). ${ }^{34}$

Organizational structure with shared reporting to either the VP, Hospital Operations and CIO or the Corporate Director of Telehealth. Ultimately, all departments are under the control of the VP, Hospital Operations and CIO. (Large-sized 20+ hospital international health system) ${ }^{34}$

\section{USING GOVERNANCE TO PRIORITIZE TELEHEALTH PROGRAM, INITIATIVE, OR COMPANY INVESTMENT}

Ongoing systematic review and prioritization of telehealth services complement telehealth governance and the appropriate and aligned investment to operating and capital budgets. This includes starting new programs and prioritizing or vetoing recommendations to optimize and expand services. A proven approach is assessment, with consideration of a defined organizational telehealth methodology. 


\section{Organizational Structure}

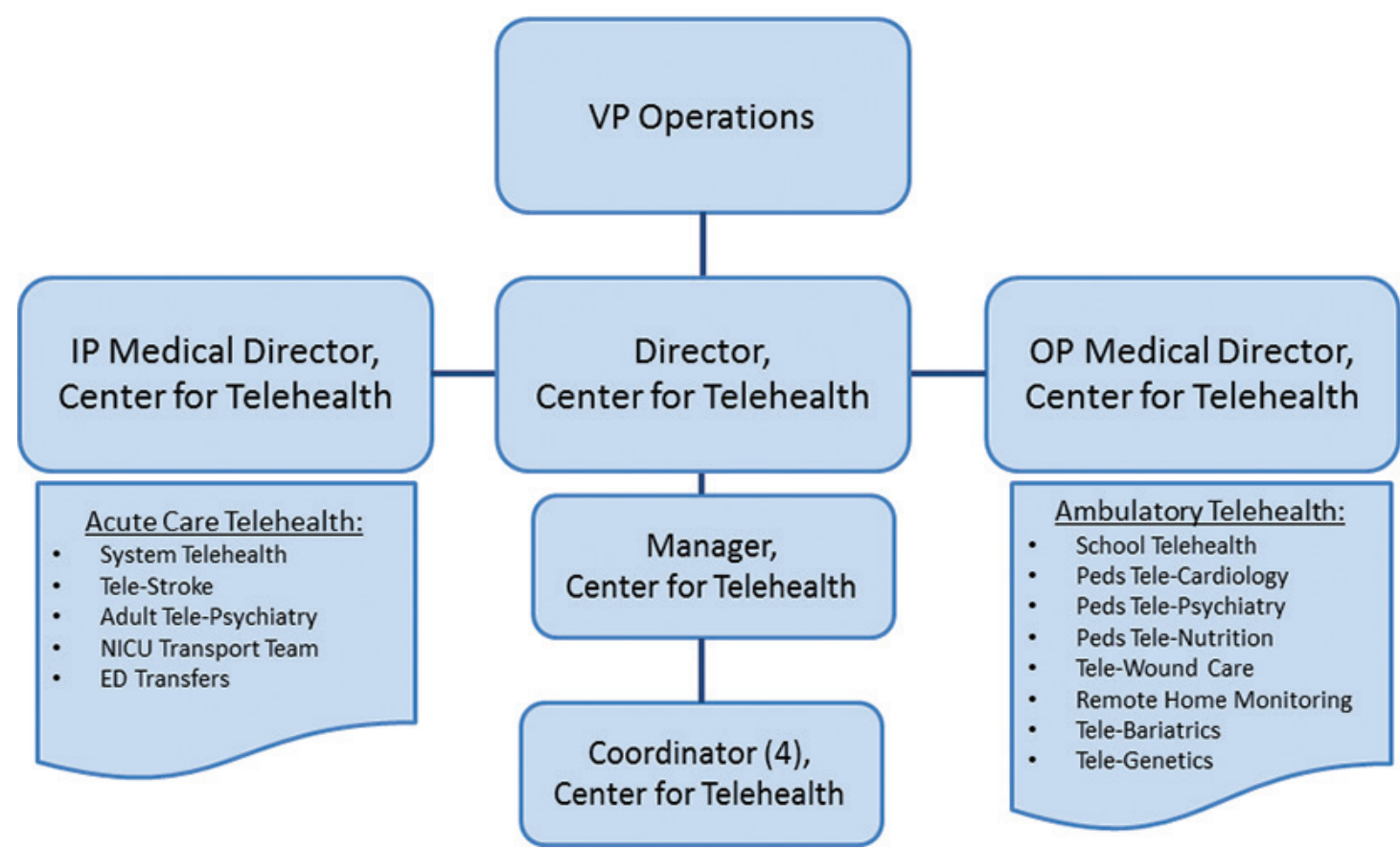

Figure 3-Example of organizational structure.

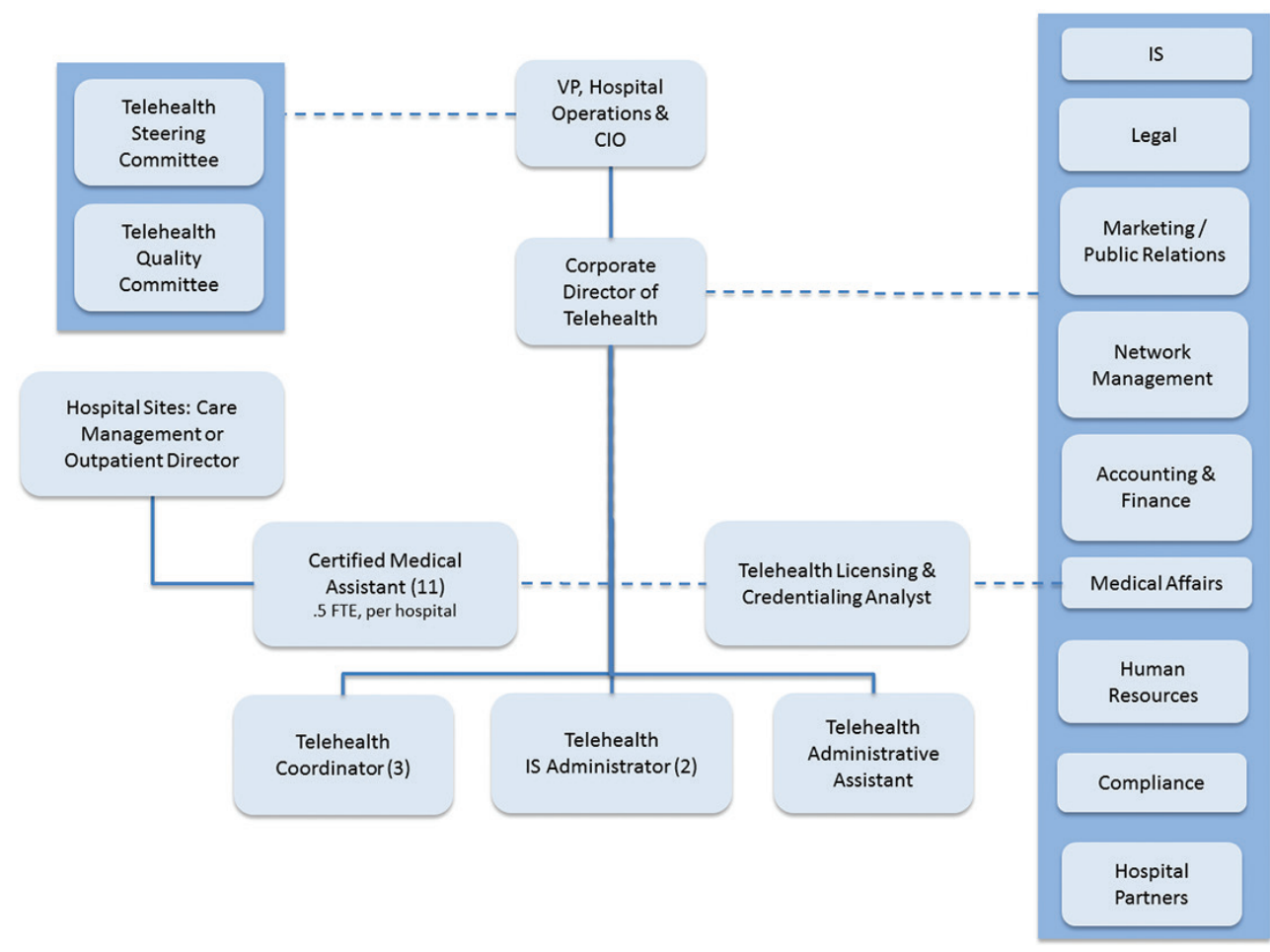

Figure 4-Example of organizational structure. 
Methodology used by telehealth programs, initiatives, and companies include, but are not limited, to the following:

1. Clinical value: Implementing the telehealth program, initiative, or company significantly improves patient experience and access, while reducing cost and improving quality.

2. Physician/provider engagement: A physician or provider champion candidate is present with significant buy-in from colleagues in the clinical discipline. A strong team and team lead are present with a lead backup.

3. Administrative support: Senior leadership supports and validates the physician or provider champion and the clinical discipline's strength for successful implementation. Appropriate legal and risk counsel has been contacted.

4. Strategic plan congruence: The clinical discipline and the telehealth program, initiative, or company align with the organization's strategic plan.

5. Access to funding and technology: The clinical discipline, or if present, telehealth office/department, has access to funding (organizational funding/capital, federal grant, industry grant, foundation/association grant, or other). Technology may exist or new technology investment may be required. The initiative's reimbursement, ROI and VOI, is understood.

6. Clinical capacity: The clinical discipline has the capacity (i.e., time and manpower) for successful implementation of shortterm and long-term projects $(1,3$, and 5 years). Implementing impacts capacity for the clinical discipline in a positive and manageable way.

7. Operational and logistical complexity: Ease of implementation does not pose major operational barriers. Pre-work may or may not be accomplished to date.

\section{CONCLUSIONS}

Telehealth finance and successful telehealth business models are sources of insight to a metamorphosis continuing to demonstrate value to the respective stakeholders of telehealth programs, initiatives, and companies. The design and vision for an excellent telehealth business model are not a fortuitous product, but rather a creative organization of key financial variables and governance with a focus on delivering highquality patient care through technology.

Funding Statement: This research received no specific grant from any funding agency in the public, commercial, or not-for-profit sectors.

Conflict of Interest: The authors have reported no conflicts of interest.

Contributors: Mr Bryan T. Arkwright was the primary lead author and performed all the writing, editing, and literature review/research. Ms Monica Leslie assisted in writing and editing of the article. Ms Morgan Light assisted in the literature review and references for this article.

\section{REFERENCES}

1. Lighter D. Advanced performance improvement in health care: Principles and methods. Jones \& Bartlett Learning; 2009, p. 461.

2. Ozcan YA. Analytics and decision support in health care operations management. John Wiley \& Sons; 2017, p. 814.

3. Bodenheimer T, Sinsky C. From triple to quadruple aim: Care of the patient requires care of the provider. Ann Fam Med. 2014;12(6):573-576. [cited 2019 Mar 7]. Available from: http://www.annfammed. org/content/12/6/573.full

4. Lunney M, Lee R, Tang K, et al. Impact of Telehealth interventions on processes and quality of care for patients with ESRD. 
Am J Kidney Dis. 2018 Apr 23 [cited 2018 May 21];0(0). Available from: https://www. ajkd.org/article/S0272-6386(18)30547-X/ abstract

5. Kulcsar M, Gilchrist S, George MG. Improving stroke outcomes in rural areas through telestroke programs: An examination of barriers, facilitators, and state policies. Telemed J E-Health Off J Am Telemed Assoc. 2014 Jan;20(1):3-10.

6. Mechanic OJ, Kimball AB. Telehealth systems. In: StatPearls. Treasure Island, FL: StatPearls Publishing; 2018 [cited 2018 Jul 13]. Available from: http://www.ncbi.nlm. nih.gov/books/NBK459384/

7. Medicare Payments for Telehealth Increased $28 \%$ in 2016: What you should know. [cited 2018 Jul 13]. Available from: http:// www.foley.com/medicare-payments-fortelehealth-increased-28-in-2016-what-youshould-know-08-28-2017/

8. Lacktman N. OIG report: CMS paid practitioners for Telehealth services that did not meet Medicare requirements. Health Care Law Today. 2018 [cited 2018 May 21]. Available from: https://www. healthcarelawtoday.com/2018/04/16/ oig-report-cms-paid-practitioners-fortelehealth-services-that-did-not-meetmedicare-requirements/

9. CMS paid practitioners for Telehealth services that did not meet Medicare requirements audit (A-05-16-00058) 0405-2018. [cited 2018 Jul 13]. Available from: https://oig.hhs.gov/oas/reports/ region5/51600058.asp

10. Humer MF, Campling BG. The role of telemedicine in providing thoracic oncology care to remote areas of British Columbia. Curr Oncol Rep. 2017 Aug 1;19(8):52.

11. Edgerton SS. A pilot study investigating employee utilization of corporate telehealth services. Perspect Health Inf Manag. 2017 Oct 1 [cited 2018 May 21];14(Fall). Available from: https://www.ncbi.nlm.nih. gov/pmc/articles/PMC5653955/

12. Binder W, Cook J, Gramze N, Airhart $\mathrm{S}$. Telemedicine in the intensive care unit: Improved access to care at what cost? Crit Care Nurs Clin N Am. 2018 Jun;30(2):289-96.

13. Chen J, Sun D, Yang W, et al. Clinical and economic outcomes of telemedicine programs in the intensive care unit: A systematic review and meta-analysis.

J Intensive Care Med. 2017 Aug 22;0885066617726942.

14. Plazzotta F, Sommer JA, Marquez Fosser SN, Luna DR. Asynchronous dermatology teleconsultations using a personal health record. Stud Health Technol Inform. 2018;247:690-4.

15. Rat C, Hild S, Serandour J, et al. JMIRuse of smartphones for early detection of melanoma: Systematic review | Rat | $J$ Med Internet Res. 2018 [cited 2018 May 21];20(4). Available from: http://www.jmir. org/2018/4/e135/

16. Flaten HK, St Claire C, Schlager E, Dunnick CA, Dellavalle RP. Growth of mobile applications in dermatology - 2017 update. Dermatol Online J. 2018 Jan 1 [cited 2018 May 21];24(2). Available from: https://escholarship-org.proxy.lib.ohio-state. edu/uc/item/3hs7n9z6

17. Charlston S, Siller G. Teledermatologist expert skin advice: A unique model of care for managing skin disorders and adverse drug reactions in hepatitis C patients. Aust J Dermatol. 2018 Nov;59(4):315-317. doi: 10.1111/ ajd.12803. Epub 2018 Mar 23.

18. Veazie S, Winchell K, Gilbert J, et al. Rapid evidence review of mobile applications for self-management of diabetes. J Gen Intern Med. 2018 May 8;1-10.

19. Lunde P, Nilsson BB, Bergland A, Kværner KJ, Bye A. The effectiveness of smartphone apps for lifestyle improvement in noncommunicable diseases: Systematic review and meta-analyses. $J$ Med Internet Res. 2018;20(5):e162.

20. Tudor-Sfetea C, Rabee R, Najim M, et al. Evaluation of two mobile health apps in the context of smoking cessation: Qualitative study of Cognitive Behavioral 
Therapy (CBT) versus non-CBT-based digital solutions. JMIR MHealth UHealth. 2018;6(4):e98.

21. Center for Connected Health Policy. Telehealth policy barriers. National Organization of State Offices of Rural Health; 2016.

22. Duff-Brown B. FSI $\mid$ CHP/PCOR Measuring return on investment in healthcare. 2016 [cited 2018 Jul 13]. Available from: https:/healthpolicy.fsi.stanford.edu/news/ global-health-economics-consortium-tacklescomplex-issue-societal-returns-health-care

23. Leslie M, Virani R. Realizing value with Telehealth in Chronic Condition Management (CCM) programs. Poster presented at 2016.

24. Queens University Smith School of Business Study. 2018.

25. Medicare Learning Network. Telehealth services. 2018.

26. Beware the telemedicine Trojan Horse MedCity News. [cited 2018 Jul 13]. Available from: https://medcitynews.com/2017/09/ beware-telemedicine-trojan-horse/

27. Eramo L. How to measure ROI of telemedicine: An Oklahoma health system shares some insights - MedCity News. 2017 [cited 2018 May 21]. Available from: https:// medcitynews.com/2017/04/how-to-measureroi-of-telemedicine/?rf=1

28. Community Paramedicine Remote Patient Monitoring (CPRPM): Benefits evaluation \& lessons learned 2015/17. 2018.

29. Berman SJ, Wada C, Minatodani D, et al. Home-based preventative care in high-risk dialysis patients: A pilot study. Telemed E-Health. 2011 Apr 11;17(4):283-7.

30. Qubty W, Patniyot I, Gelfand A. Telemedicine in a pediatric headache clinic: A prospective survey. Neurology. 2018 [cited 2018 May 21]; Available from: http://n. neurology.org/content/90/19/e1702.long

31. Walsh T, Goerlich C. You're probably measuring telehealth ROI wrong. Use these 6 metrics to do it right. 2017 [cited 2018 Jul 13]. Available from: http://www.advisory.com/research/ market-innovation-center/the-growthchannel/2017/05/telehealth-roi

32. A guide for telemedicine service vendor contracting: Applying traditional contracting considerations in a new arena. [cited 2019 Feb 18]. Available from: https://www.bakerdonelson. com/a-guide-for-telemedicine-servicevendor-contracting-applying-traditionalcontracting-considerations-in-a-new-arena

33. Molfenter T, Brown R, O’Neill A, Kopetsky E, Toy A. Use of telemedicine in addiction treatment: Current practices and organizational implementation characteristics. Int J Telemed Appl. 2018 Mar 11 [cited 2018 May 21];2018. Available from: https://www.ncbi.nlm.nih. gov/pmc/articles/PMC5866865/

34. Arkwright B, Jones J, Osborne T, Glorioso G, Russo J. View of telehealth governance: An essential tool to empower today's healthcare leaders. [cited 2018 Jul 23]; Available from: https:// telehealthandmedicinetoday.com/index.php/ journal/article/view/12/5

35. Overdijkink SB, Velu AV, Rosman AN, van Beukering MD, Kok M, Steegers-Theunissen RP. The usability and effectiveness of mobile health technology-based lifestyle and medical intervention apps supporting health care during pregnancy: Systematic review. JMIR MHealth UHealth. 2018 Apr 24;6(4):e109.

Copyright Ownership: This is an open access article distributed in accordance with the Creative Commons Attribution Non Commercial (CC BY-NC 4.0) license, which permits others to distribute, adapt, enhance this work non-commercially, and license their derivative works on different terms, provided the original work is properly cited and the use is noncommercial. See: http://creativecommons. org/licenses/by-nc/4.0. 